\title{
Comparative Analysis Of Cellular Beam And Honeycomb Beam With Anasys Program
}

\author{
Alvin Hogan M. Situmorang \\ Department Of Civil Engineering, University Of North Sumatra, Jl. Dr. Mansur No. 9 Padang Bulan, Kec. \\ Medan Baru, Kota Medan 20222
}

\begin{tabular}{|c|c|}
\hline ARTICLE INFO & ABSTRACT \\
\hline Article history: & \multirow{3}{*}{$\begin{array}{l}\text { Steel is one of the most widely used construction materials. Along } \\
\text { with the development of technology in the field of construction, many } \\
\text { variations have been made in the use of steel as a construction } \\
\text { material to make it more suitable for the needs and economical in } \\
\text { terms of cost. One of the innovations that is often used in steel is to } \\
\text { make holes in the body to increase the height of the steel profile. } \\
\text { The shape of the hole that is usually formed on the body varies. The } \\
\text { most frequently used variations are the hexagon shape (honeycomb } \\
\text { beam) and the circular beam (cellular beam). In this study, we will } \\
\text { compare the honeycomb beam and the cellular beam. The two } \\
\text { beams will be made in several variations with D/Do and S/Do } \\
\text { parameters. The experiment was carried out using the ANSYS } \\
\text { program. Comparisons are made to find a beam that has a better } \\
\text { ability than the parameter variations on the two beams From the } \\
\text { results of the study, it was found that the best parameter variations } \\
\text { were } D / D o=1.6 \text { and } S / D o=1.08 \text { for honeycomb beam. For cellular } \\
\text { beam } D / D o=1.6 \text { and } S / D o=1.28 \text { which is better. Then from the } \\
\text { comparison of cellular beam and honeycomb beam, it is found that } \\
\text { the honeycomb beam is better. }\end{array}$} \\
\hline $\begin{array}{r}\text { Received Feb 01, } 2021 \\
\text { Revised Mar 05, } 2021 \\
\text { Accepted Apr 30, } 2021\end{array}$ & \\
\hline $\begin{array}{r}\text { Keywords: } \\
\text { Cellular Beam } \\
\text { Honeycomb } \\
\text { Anasys }\end{array}$ & \\
\hline
\end{tabular}

This is an open access article under the CC BY-NC license.

\section{Corresponding Author:}

Alvin Hogan M. Situmorang ,

Department Of Civil Engineering,

University Of North Sumatra,

Jl. Dr. Mansur No. 9 Padang Bulan, Kec. Medan Baru, Kota Medan 20222.

Email : alvinsitumorang@gmail.com

\section{INTRODUCTION}

Nowadays, steel construction is an alternative in the construction of buildings or other structures, both on a small and large scale. Therefore, steel is widely used for structures with the type of height, width and other types of structures. So that with the development of technology and the increasing need for the use of steel in structures, scientists make innovations to increase the strength of steel at a more economical price.

A planner in planning a structure must not only consider the safety and serviceability of the structure, but he must also consider the functional requirements based on the use of the building structure. When planning a structure in a high-rise building, the conventional steel structure consists of beams and girders with steel whose body parts are still solid. This makes it difficult for the placement of pipes, ducts and air conditioners that require functional satisfaction for their location in the structure. As a result of this, the scientists developed a system of openings in the 
steel body to facilitate installation services and also to maintain the installation on a regular basis and for a long period of time.

Steel with openings in the body is profile I steel which is made by cutting the standard profile body into 2 parts along the span, then separated, shifted and welded back into a new shape (JP Boyer, 1964). The result of this process makes the steel profile has a higher height than the beginning, resulting in the addition of inertia. As the inertia increases, the strength of the steel increases. The economic value of the I profile can be increased, because the initial I profile with smaller dimensions and lighter weight can be formed into a profile that has a higher height. The shape of the opening in the steel body will depend on the designer's choice and the desired opening. There is no fixed rule to govern the shape of an existing opening. But for the convenience of the planner, prefer to use openings with a symmetrical shape. Steel beams with openings are usually called castellated beams. There are several forms of openings in steel that are usually used such as honeycomb beams with hexagon-shaped openings and cellular beams with circular openings.

\section{RESEARCH METHOD}

The research method used in this final project is a literature review method in which the required data are assumed to be based on field conditions. The following is the sequence of this research:

a. Looking for basic literature describing cellular beam, honeycomb beam and ANSYS

b. Basic discussion about the advantages of cellular beam and honeycomb beam.

c. Plan IWF into cellular beam and honeycomb beam, then perform analysis using ANSYS.

d. Processing the data obtained by ANSYS, then making comparisons to the cellular beam and honeycomb beam.

This research is an experimental experiment on several forms of variation of openings in the steel profile body. In this research, two applications are used. The first application is SolidWorks which is only used to simplify the process of drawing steel profile models with openings in the body. The next application is ANSYS to analyze the ability of steel profiles that have openings in the body.

The test object that is planned and analyzed in this research is a steel profile that is formed in such a way that it has openings in its body. There are two types of openings in the body that will be analyzed in this study, namely cellular beam (opening with a circular shape on the body) and honeycomb beam (opening with a hexagon shape on the body). At each opening in the body, several different variations will be planned following several parameters. The parameters used to make variations are the height of the opening in the steel profile body and the distance between the center point to the center point of the opening in the steel profile body. Each variation will be done the same for the cellular beam and honeycomb beam.

The research was carried out on steel profiles with openings in the body that functioned as beams. The supports used in the beam are simple supports (beams with joint and roller supports). The beam is given a concentrated load at the center of the span. The span length of the beam elements for the cellular beam and honeycomb beam to be analyzed is the same length for each variation of the modeling of the two beams. From the results obtained from the analysis will be compared the deflections and stresses that occur. The flow chart below will explain in general the process of doing this research from beginning to end.

\section{RESULTS AND DISCUSSIONS}

\subsection{Experimental Data}

The following are the results of the data obtained from ANSYS for each variation carried out. The first table below is a table of results from the initial profile.

Table 1. Data Table of Initial Profile Results

\begin{tabular}{ccc}
\hline & WF 400X200 & \\
Style $(\mathrm{N})$ & Voltage (MPa) & Deflection $(\mathrm{mm})$ \\
\hline
\end{tabular}




\begin{tabular}{ccc}
\hline 5000 & 14.98 & 2.0578 \\
10000 & 29.946 & 4.1158 \\
15000 & 44,896 & 6.1741 \\
20000 & 59,832 & 8.2325 \\
25000 & 74.753 & 10,291 \\
30000 & 89,659 & 12.35 \\
35000 & 104.55 & 14,409 \\
40000 & 119.43 & 16,469 \\
45000 & 134.29 & 18,528 \\
50000 & 149.14 & 20.588 \\
55000 & 163.97 & 22,648 \\
60000 & 178.79 & 24.708 \\
65000 & 193.59 & 26,768 \\
70000 & 208.38 & 28.828 \\
75000 & 223.18 & 30.9 \\
80000 & 237.92 & 32,952 \\
85000 & 252.67 & 35,013 \\
90000 & 267.4 & 37,074 \\
95000 & 282.12 & 39,135 \\
100000 & 296.84 & 41,197 \\
105000 & 249.55 & 43,268 \\
110000 & 249.76 & 45,354 \\
115000 & 249.92 & 47,459 \\
120000 & 250.09 & 49,586 \\
125000 & 250.25 & 51,802 \\
130000 & 251.1 & 54.579 \\
135000 & 252.91 & 59,045 \\
140000 & 257.9 & 72,764 \\
145000 & & \\
\hline
\end{tabular}

\section{a. Model 1}

Table 2. Results Data Table (Model 1)

\begin{tabular}{|c|c|c|c|c|}
\hline \multirow{3}{*}{ Style (N) } & \multicolumn{3}{|c|}{ Model $1(\mathrm{~S} / \mathrm{Do}=1.28 ; \mathrm{D} / \mathrm{Do}=1,4)$} & \\
\hline & \multicolumn{2}{|c|}{ Cellular Beam } & Honeycomb Beam & \\
\hline & Voltage (MPa) & Deflection(mm) & Voltage (MPa) & Deflection $(\mathrm{mm})$ \\
\hline 5000 & 11.03 & 1.0838 & 10,616 & 0.98523 \\
\hline 10000 & 22.05 & 2.1677 & 21,242 & 1.9705 \\
\hline 15000 & 33,059 & 3.2517 & 31,878 & 2.9559 \\
\hline 20000 & 44,059 & 4.3357 & 42.523 & 3.9413 \\
\hline 25000 & 55,048 & 5.4198 & 53,178 & 4.9268 \\
\hline 30000 & 66.028 & 6.504 & 63.843 & 5,9123 \\
\hline 35000 & 76,997 & 7.5882 & 74.517 & 6,898 \\
\hline 40000 & 87,957 & 8.6725 & 85,202 & 7.8836 \\
\hline 45000 & 98,906 & 9.7569 & 95.896 & 8.8694 \\
\hline 50000 & 109.85 & 10,841 & 106.6 & 9.8552 \\
\hline 55000 & 120.78 & 11,926 & 117.31 & 10,841 \\
\hline 60000 & 131.7 & 13,011 & 128.04 & 11,827 \\
\hline 65000 & 142.61 & 14,095 & 138.79 & 12,811 \\
\hline 70000 & 153.51 & 15.18 & 149.51 & 13.8 \\
\hline 75000 & 164.4 & 16,265 & 160.26 & 14.786 \\
\hline 80000 & 175.28 & 17.35 & 171.03 & 15,774 \\
\hline 85000 & 186.15 & 18,435 & 181.81 & 16,762 \\
\hline 90000 & 197.01 & 19.52 & 192.6 & 17,752 \\
\hline 95000 & 207.86 & 20.605 & 203.4 & 18,743 \\
\hline 100000 & 218.7 & 21.69 & 214.21 & 19,736 \\
\hline 105000 & 229.54 & 22.775 & 225.04 & 20.731 \\
\hline 110000 & 240.36 & 23.86 & 235.88 & 21,728 \\
\hline 115000 & 251.17 & 24,946 & 246.73 & 22,728 \\
\hline 120000 & 261.98 & 26,032 & 257.6 & 23,731 \\
\hline 125000 & 272.81 & 27.12 & 268.52 & 24,738 \\
\hline 130000 & 265.38 & 28,212 & 271.84 & 25,748 \\
\hline 135000 & 273.37 & 29,311 & 272.23 & 26,764 \\
\hline
\end{tabular}




\begin{tabular}{lllll}
\hline 140000 & 275.91 & 30,418 & 280.47 & 27,786 \\
145000 & 267.52 & 31,536 & 264.16 & 28.817 \\
150000 & 267.36 & 32,672 & 262.35 & 29,858 \\
155000 & 255.62 & 33,826 & 267.25 & 30,912 \\
160000 & 248.47 & 35,011 & & \\
165000 & 248.51 & 36,238 & & >error \\
170000 & 248.5 & 37,579 & & \\
175000 & 248.91 & 39,316 & & \\
180000 & 249.75 & 41,995 & & \\
185000 & \multicolumn{7}{c}{ >error } & & & \\
\hline
\end{tabular}

\section{b. $\quad$ Model 2}

Table 3. Results Data Table (Model 2)

\begin{tabular}{|c|c|c|c|c|}
\hline \multirow{3}{*}{ Style (N) } & \multicolumn{3}{|c|}{ Model $2(\mathrm{~S} / \mathrm{Do}=1.28 ; \mathrm{D} / \mathrm{Do}=1.5)$} & \\
\hline & \multicolumn{2}{|c|}{ Cellular Beam } & \multicolumn{2}{|c|}{ Honeycomb Beam } \\
\hline & Voltage (MPa) & Deflection $(\mathrm{mm})$ & Voltage (MPa) & Deflection $(\mathrm{mm})$ \\
\hline 5000 & 11,346 & 1.1096 & 10.86 & 1.0197 \\
\hline 10000 & 22,682 & 2.2193 & 21.71 & 2.0395 \\
\hline 15000 & 34.006 & 3,329 & 32.55 & 3.0593 \\
\hline 20000 & 45.32 & 4.4389 & 43,381 & 4.0792 \\
\hline 25000 & 56.623 & 5.5488 & 54,203 & 5.0992 \\
\hline 30000 & 67,915 & 6.6588 & 65,015 & 6.1193 \\
\hline 35000 & 79,196 & 7.7688 & 75.819 & 7.1394 \\
\hline 40000 & 90,467 & 8.879 & 86.612 & 8.1596 \\
\hline 45000 & 101.73 & 9.9892 & 97.397 & 9.1799 \\
\hline 50000 & 112.98 & 11.1 & 108.17 & 10.2 \\
\hline 55000 & 124.22 & 12.21 & 118.94 & 11.221 \\
\hline 60000 & 135.44 & 13.321 & 129.69 & 12,241 \\
\hline 65000 & 146.49 & 14,492 & 140.44 & 13,261 \\
\hline 70000 & 157.87 & 15.54 & 151.18 & 14,283 \\
\hline 75000 & 169.07 & 16,651 & 161.91 & 15,303 \\
\hline 80000 & 180.25 & 17,762 & 172.63 & 16,325 \\
\hline 85000 & 191.43 & 18,873 & 183.35 & 17.347 \\
\hline 90000 & 202.6 & 19.984 & 194.05 & 18,369 \\
\hline 95000 & 213.75 & 21,095 & 204.75 & 19,393 \\
\hline 100000 & 224.9 & 22.206 & 215.44 & 20,417 \\
\hline 105000 & 236.03 & 23,317 & 226.12 & 21.442 \\
\hline 110000 & 247.16 & 24,428 & 236.8 & 22,469 \\
\hline 115000 & 258.27 & 25.539 & 247,47 & 23,498 \\
\hline 120000 & 269.37 & 26,651 & 258.13 & 24,529 \\
\hline 125000 & 270.72 & 27,763 & 268.83 & 25.562 \\
\hline 130000 & 273.88 & 28.878 & 268,78 & 26,599 \\
\hline 135000 & 277.04 & 29.9996 & 272.23 & 27,641 \\
\hline 140000 & 267.78 & 31,12 & 276.4 & 28,688 \\
\hline 145000 & 260.97 & 32.252 & 265.79 & 29,743 \\
\hline 150000 & 254.88 & 33,395 & 266.83 & 30,806 \\
\hline 155000 & 256.9 & 34,552 & 258.44 & 31.88 \\
\hline 160000 & 248.3 & 35.73 & 254.25 & 32,968 \\
\hline 165000 & 248.34 & 36,948 & 248.11 & 34,077 \\
\hline 170000 & 248.37 & 38,306 & 248,12 & 35,241 \\
\hline 175000 & 248,88 & 40,096 & 248.27 & 36,578 \\
\hline 180000 & 249.97 & 42,758 & 248.87 & 38,322 \\
\hline 185000 & & & 249.59 & 40,958 \\
\hline 190000 & & & & \\
\hline
\end{tabular}

c. Model 3

Table 4. Results Data Table (Model 3)

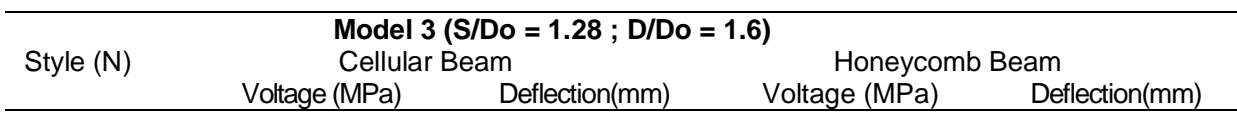




\begin{tabular}{|c|c|c|c|c|}
\hline 5000 & 10,922 & 1.1576 & 11,112 & 1.0673 \\
\hline 10000 & 21,836 & 2.3152 & 22.215 & 2.1346 \\
\hline 15000 & 32.74 & 3,473 & 33.308 & 3,202 \\
\hline 20000 & 43,636 & 4.6308 & 44,392 & 4.2695 \\
\hline 25000 & 54.523 & 5.7887 & 55,466 & 5.3371 \\
\hline 30000 & 65.4 & 6.9466 & 66,531 & 6.4047 \\
\hline 35000 & 76.269 & 8.1047 & 77,587 & 7.4724 \\
\hline 40000 & 87,129 & 9.2628 & 88,633 & 8.5402 \\
\hline 45000 & 97.98 & 10,421 & 99.67 & 9.6081 \\
\hline 50000 & 108.82 & 11,579 & 110.7 & 10,676 \\
\hline 55000 & 119.66 & 12,738 & 121.72 & 11,744 \\
\hline 60000 & 130.48 & 13,896 & 132.73 & 12,812 \\
\hline 65000 & 141.3 & 15,056 & 143.73 & 13,881 \\
\hline 70000 & 152.1 & 16,213 & 154.72 & 14.948 \\
\hline 75000 & 162.9 & 17,372 & 165.7 & 16.017 \\
\hline 80000 & 173.69 & 18,531 & 176.67 & 17.085 \\
\hline 85000 & 184.47 & 19.69 & 187.64 & 18,154 \\
\hline 90000 & 195.25 & 20.849 & 198.59 & 19,222 \\
\hline 95000 & 206.01 & 22.008 & 209.54 & 20,291 \\
\hline 100000 & 216.77 & 23,167 & 220.48 & 21.36 \\
\hline 105000 & 227.52 & 24,326 & 231.41 & 22.43 \\
\hline 110000 & 238.25 & 25,485 & 242.33 & 23.5 \\
\hline 115000 & 248.99 & 26,644 & 253.25 & 24,571 \\
\hline 120000 & 259.71 & 27,804 & 264.16 & 25,643 \\
\hline 125000 & 258.95 & 28,966 & 272.85 & 26,717 \\
\hline 130000 & 268.45 & 30,13 & 269.58 & 27,794 \\
\hline 135000 & 270.29 & 31,298 & 278.66 & 28.875 \\
\hline 140000 & 258.11 & 32.472 & 269.68 & 29,962 \\
\hline 145000 & 263.62 & 33,655 & 267.21 & 31.056 \\
\hline 150000 & 258,68 & 34,849 & 259.83 & 32.157 \\
\hline 155000 & 255.14 & 36,059 & 248,48 & 33,269 \\
\hline 160000 & 248.28 & 37,294 & 248.55 & 34,395 \\
\hline 165000 & 248.37 & 38,615 & 248.59 & 35.572 \\
\hline 170000 & 248.84 & 40,217 & 248.61 & 36.801 \\
\hline 175000 & 249.86 & 42,362 & \multirow{3}{*}{\multicolumn{2}{|c|}{ >error }} \\
\hline 180000 & 251.35 & 45,916 & & \\
\hline 185000 & & & & \\
\hline
\end{tabular}

\section{d. Model 4}

Table 5. Results Data Table (Model 4)

\begin{tabular}{ccccc}
\hline \multirow{2}{*}{ Style $(\mathrm{N})$} & \multicolumn{2}{c}{ Model 4 (S/Do $\mathbf{1 . 1 8} ; \mathbf{D} / \mathbf{D o}=\mathbf{1 . 4}$} & \multicolumn{2}{c}{ Honeycomb Beam } \\
& Voltage $(\mathrm{MPa})$ & $\begin{array}{c}\text { Deam } \\
\text { Deflection }(\mathbf{m m})\end{array}$ & Voltage $(\mathrm{MPa})$ & Deflection(mm) \\
\hline 5000 & 10,944 & 1.1343 & 10.51 & 0.9865 \\
10000 & 21,877 & 2.2686 & 21,012 & 1.9731 \\
15000 & 32,799 & 3,403 & 31,504 & 2.9597 \\
20000 & 43,712 & 4,5374 & 41,988 & 3.9464 \\
25000 & 54,614 & 5.6719 & 52.463 & 4.9331 \\
30000 & 65.505 & 6.8064 & 62.93 & 5.92 \\
35000 & 76.386 & 7,941 & 73.388 & 6.9069 \\
40000 & 87,257 & 9.0756 & 83.837 & 7.8938 \\
45000 & 98,118 & 10.21 & 94.277 & 8.8808 \\
50000 & 108.97 & 11,345 & 104.71 & 9.8679 \\
55000 & 119.81 & 12.48 & 115.13 & 10,855 \\
60000 & 130.64 & 13.615 & 125.55 & 11,842 \\
65000 & 141.46 & 14.75 & 135.95 & 12,828 \\
70000 & 152.27 & 15,884 & 146.35 & 13,818 \\
75000 & 163.07 & 17.019 & 156.74 & 14,805 \\
80000 & 173.86 & 18,154 & 167.12 & 15,792 \\
85000 & 184.64 & 19,289 & 177.5 & 16.78 \\
90000 & 195.41 & 20,424 & 187.86 & 17,769 \\
95000 & 206.17 & 21.559 & 198.22 & 18,759 \\
100000 & 216.92 & 22,696 & 208.58 & 19.75 \\
105000 & 227.66 & 23,842 & 218.92 & 20.743 \\
110000 & 238.39 & 25.002 & 229.26 & 21,738 \\
\hline
\end{tabular}




\begin{tabular}{lcccc}
\hline 115000 & 249.12 & 26,181 & 239.59 & 22,734 \\
120000 & 259.85 & 27,382 & 249.92 & 23,732 \\
125000 & 270.64 & 28,606 & 260.24 & 24,733 \\
130000 & 271.97 & 29,861 & 266.42 & 25.737 \\
135000 & 277.41 & 31,166 & 266.58 & 26,747 \\
140000 & 274.88 & 32.545 & 275.64 & 27,762 \\
145000 & 269.84 & 34,035 & 272.5 & 28,786 \\
150000 & 270.39 & 35,718 & 263.77 & 29.82 \\
155000 & 256.3 & 37,775 & 263.71 & 30,863 \\
160000 & 248.3 & 40,837 & 255.03 & 31,917 \\
165000 & 248.4 & 45.799 & 250.3 & 32,993 \\
170000 & 248.46 & 52.48 & 251.4 & 34,104 \\
175000 & 248.92 & 61.343 & 248.41 & 35,294 \\
180000 & & & 248.72 & 36,746 \\
185000 & & & 249.41 & \multicolumn{2}{c}{$>$} \\
190000 & & & & \multicolumn{2}{c}{ >error } \\
\hline
\end{tabular}

\subsection{Experimental Data Analysis}

At this stage, the data from the experimental results will be analyzed which can be seen in the tables in the previous subchapter. The analysis will be presented in the form of a line graph based on the result data. The analysis will be divided into 3 parts based on the profile height or D/Do parameters.

\section{a. $\quad$ Result Analysis $\mathrm{D} / \mathrm{Do}=\mathbf{1 . 4}$}

In this section, a graph of the stresses and deformations that occur due to loading from Model 1 , Model 4 and Model 7 will be shown which have the same height with the difference in the distance $\mathrm{S}$.

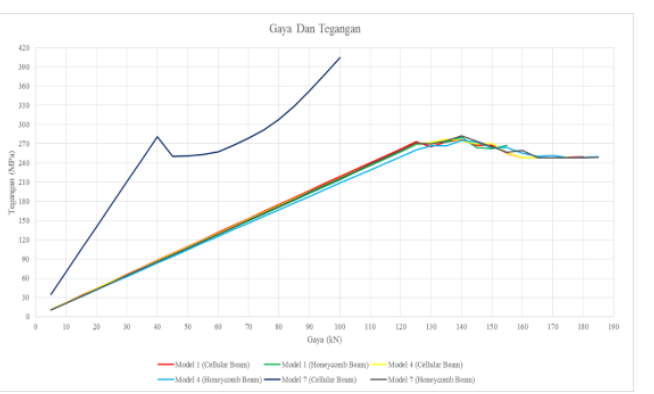

Figure 1. Stress Occurs Due to Loading $(\mathrm{D} / \mathrm{Do}=1,4)$

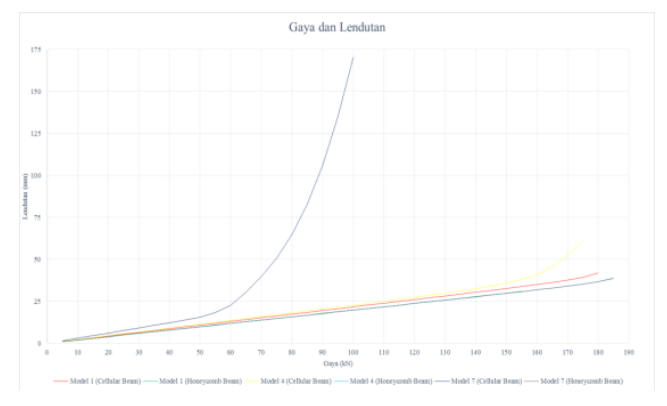

Figure 2. Deflection Occurs Due to Loading $(\mathrm{D} / \mathrm{Do}=1,4)$

The results of the analysis of the graph above:

1) The loading is carried out in stages of $5000 \mathrm{~N}$ at each stage until the profile is declared unstable or an error occurs in the analysis carried out by the ANSYS program. 
2) From the graph above, it can be seen that the Model 1 Cellular Beam is capable of carrying a load of $180 \mathrm{kN}$. For the Honeycomb Beam, the load that can be carried by Models 4 and 7 is $185 \mathrm{kN}$.

3) In Model 7 cellular beam, the smallest load that can be carried is $100 \mathrm{kN}$. For the honeycomb beam, the smallest load occurs in Model 1 which is $155 \mathrm{kN}$.

4) The maximum stress that occurs in the cellular beam Model 7 is $404.32 \mathrm{MPa}$, which is higher than the other models.

5) In Model 1 honeycomb beam the smallest deflection is $30.912 \mathrm{~mm}$ when compared to other models.

6) In the cellular beam Model 7, the largest deflection occurs compared to other models, which is $170,29 \mathrm{~mm}$.

7) With the $\mathrm{D} / \mathrm{Do}$ ratio $=1.4$, from the analysis results it can be seen that the $\mathrm{S} / \mathrm{Do}$ ratio $=1.28$ is more suitable for cellular beams. For honeycomb beams, the $S / D$ o ratio of 1.18 and 1.08 is more suitable.

8) When viewed on Model 7 , the ratio $S / D o=1.08$ is not suitable for use in cellular beam.

\subsection{Comparison of Cellular Beam and Honeycomb Beam}

In the previous subsection, we have discussed the magnitude of the stresses and deflections that occur due to the gradual loading of the cellular and honeycomb beams. From the data, it can be seen that the load that can be carried by each beam can be seen. However, due to the step of increasing the load every $5 \mathrm{kN}$, it cannot be seen the final load that can be carried by the beam.

In this section, a re-analysis is carried out to find the load that can be carried by the beam without loading stages on the beam model that has the same load that can be carried. So that the critical load is obtained before ANSYS declares the beam unstable. After knowing the beam that bears the greatest load from several models of cellular beam and honeycomb beam, it will be compared with the initial profile.

The results in the previous subsection, it can be seen that the Model 9 honeycomb beam is a beam that can carry a larger load. For this type of cellular beam, Models 1, 2 and 3 have the same amount of load under gradual loading. Therefore, a re-analysis of the three models was carried out. From the results obtained, the cellular beam Model 3 can carry a larger load.

Table 6. Table of Result Data

\begin{tabular}{cccc}
\hline Beam Type & Burden & Voltage & Deflection \\
\hline 400 X 200 . Profile & $140 \mathrm{kN}$ & $257.9 \mathrm{MPa}$ & $72,764 \mathrm{~mm}$ \\
Model 3 (Cellular Beam) & $184.954 \mathrm{kN}$ & $255.16 \mathrm{MPa}$ & $56,939 \mathrm{~mm}$ \\
Model 9 (Honeycomb Beam) & $195 \mathrm{kN}$ & $260.79 \mathrm{MPa}$ & 80.946 \\
\hline
\end{tabular}

\subsection{Comparison of Bending Stress and Deflection Between Analytical and ANSYS}

In this section, we will compare the flexural stresses and deflections that occur due to loading from the results obtained by analytical methods and from ANSYS. The load used is $75 \mathrm{kN}$. There are 3 points that are reviewed, namely at the top of the profile, middle and bottom. Comparisons were made on the initial profile, Model 3 cellular beam and Model 9 honeycomb beam. The formula used for the analytical method is the formula for moments, flexural stresses and deflections in beams with simple supports which are commonly used.

The deflection that occurs from ANSYS will be reviewed at 3 points, namely at the top, middle and bottom of the cross section. The flexural stresses will be reviewed in the top fiber, center of gravity and bottom fiber, then will be made in the flexural stress diagram. As shown in the following bending stress diagram: 


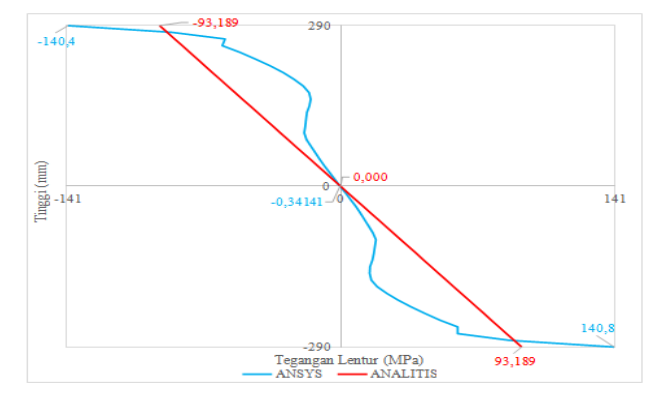

Figure 3. ANSYS and Analytical Bending Stress Diagram for Honeycomb Beam

\section{CONCLUSION}

From several models based on a variety of parameters, it is found that the ratio of $D / D o=1.6$ and $\mathrm{S} / \mathrm{Do}=1.08$ is the largest in carrying the same load for the honeycomb beam. The largest cellular beam is $\mathrm{D} / \mathrm{Do}=1.6$ and $\mathrm{S} / \mathrm{Do}=1.28$.

With the same parameters, the honeycomb beam can carry a larger load than the cellular beam.

In the process of planning honeycomb beams and cellular beams, the D/Do and S/Do parameters greatly affect the performance of the beams. So it must be considered in the planning process.

When viewed from the calculation of the inertia of the cellular beam, for the same height as the honeycomb beam, a smaller inertia will be obtained in the cellular beam. This is due to the wasted part in the cellular beam cutting process. For the larger the distance between the holes, the larger the wasted part on the cellular beam, so the larger the hole diameter and the smaller the inertia. In contrast to the honeycomb beam, the cutting process is simpler and there are no wasted parts in the cutting process.

When viewed from the cellular beam on Models 7,8 , and 9 , the ratio $S / D o=1.08$ is not very suitable for cellular beam. Because the cellular beam is more rigid to plan the distance between holes, so the distance becomes very small. In contrast to the honeycomb beam, planning the distance between holes can be more easily adjusted.

\section{REFERENCES}

Bardley, Patrick. (2007). Making Heksagonal Castellation Beam. The James F. Lincoln Arc Welding Foundation.

Blodgett, Omer W. (1991). Design of Welded Structure. Massachusetts: The James F. Lincoln Arc Welding Foundation.

Boyer, J. P. (1964). Castellated Beams - New Developement. AISC National Engineering Conference.

BSi.(1990). BS 5950 : Part $1: 1990$ : Structural Use of Steelwork.

BSN. (2002). SNI 03 - 1972 - 2001- Tata Cara Perencanaan Struktur Baja.

Fares, Sameer dan Coulson, John. (2016). Steel Design Guide 31 - Castellated and Cellular Beam Design. America: AISC.

Gere, James dan Timoshenko, Stephen. (2000). Mekanika Bahan. Jakarta : Erlangga.

Hoffman, Rebecca. (2006). Analysis of Stress Distribution and Failure Behavior of Cellular Beams.

Jamadar dan Kumbhar. (2015). Parametric Study of Castellated Beam With Circular and Diamond Shaped Opening. International Journal of Innovative Research In Advance Engineering.Vol. 2 No.2.

Kassimali, Aslam. (2011). Structural Analysis 4th Edition. Standford: Cengage Learning

Knowles, Peter. (1987). Design of Castellated Beam For Use With BS 5950 and BS 449. London: Constardo.

Lawson, R. M. (2011). Design of Composite Beam With Large Web Opening. Berkshire: SCl.

Salmon, Charles. (1997). Struktur Baja Desain dan Perilaku. Jakarta : Erlangga.

Wakchaure dan Sagade. (2012). Parametric Study of Castellated Beam With Varying Depth of Web Opening. International Journal of Sciencetific and Research Publication Vol.2 No. 